\title{
50 Anos de DADOS - Revista de Ciências Sociais: Uma Introdução à Coleção*
}

\section{Charles Pessanha}

Universidade Federal do Rio de Janeiro (UFRJ), Rio de Janeiro, RJ, Brasil. E-mail: pessanhacf@terra.com.br

\section{INTRODUÇÃO}

$\mathrm{E}$ m 2015, a comunidade científica internacional comemorou os 350 anos da revista Philosophical Transactions. Editada pela Royal Society, "the world's first science journal"1, inaugurou os conceitos de prioridade científica e arbitragem pelos pares, fornecendo modelo para os periódicos científicos contemporâneos. Desde então, as revistas científicas ou acadêmicas, como alguns preferem denominar, se multiplicaram e se destinaram basicamente a promover a comunicação dos trabalhos científicos à comunidade acadêmica e à sociedade; adotar padrões de qualidade no desenvolvimento da ciência e em sua comunicação; proporcionar critérios para a avaliação da produtividade científica de indivíduos e instituições; e assegurar a memória da ciência.

As Ciências Humanas foram tradicionalmente refratárias ao uso das revistas científicas. Mesmo nas sociedades de desenvolvimento científico avançado, o uso do livro como meio de difusão dos trabalhos acadêmicos dos pesquisadores prevalece sobre o periódico científico nessa área, embora esse quadro venha sofrendo alterações, sobretudo no caso brasileiro.

\footnotetext{
* Agradeço a Breno Bringel a leitura atenta e as sugestões.

DADOS - Revista de Ciências Sociais, Rio de Janeiro, vol. 60, n³, 2017, pp. 605 a 622.
} 
Nos últimos anos, o artigo científico e, por consequência, a revista científica passaram a ocupar um papel central no processo de avaliação da produtividade científica de indivíduos e de instituições brasileiras, com peso destacado para os critérios de classificação da carreira individual dos pesquisadores e dos programas de pósgraduação elaborados pela Coordenação de Aperfeiçoamento de Pessoal de Nível Superior (CAPES). Acrescenta-se a isso o fato de as próprias revistas terem seu desempenho submetido ao crivo de instituições que as controlam e as classificam, como os indexadores Web of Science (WoS), Scopus e Scientific Electronic Library Online (SciELO), considerados os mais importantes, e o sistema Qualis da CAPES, ao qual voltarei mais adiante ${ }^{2}$.

Outro indicador da importância que as revistas científicas de Ciências Sociais vêm ganhando é o surgimento recente de vários trabalhos em forma de artigos, teses e outros estudos utilizando os periódicos como "termômetro" da produção científica nacional e, assim, contribuindo para a compreensão de seu papel no desenvolvimento e na institucionalização das Ciências Sociais. Destaco os de Marques (2007), Amorim Neto (2010), Leite e Codato (2013), Leite (2016), Marenco (2016), Nicolau e Oliveira (2013), Oliveira (2016), entre outros. Em linha convergente, neste número especial de DADOS, três artigos analisam o conteúdo da coleção da revista com olhares diversos. São eles: “50 Anos da Revista DADOS: Uma Análise Bibliométrica do seu Perfil Disciplinar e Temático", de Luiz Augusto Campos, João Feres Júnior e Fernando Guarnieri; “Entre a 'Velha' e a 'Nova' Ciência Política: Continuidade e Renovação Acadêmica na Primeira Década da Revista DADOS (1966-1976)", de Christian Edward Cyril Lynch; e "A Sociologia e a Sociologia Política em DADOS", de André Botelho e Lucas Correia Carvalho. Uma Análise Bibliométrica do seu Perfil Disciplinar e Temático".

Como aponta Breno Bringel na apresentação deste dossiê especial, a comemoração do aniversário de cinco décadas de existência de um periódico é um fato raro no Brasil. Durante esse período, DADOS sofreu várias modificações e se transformou em um dos mais importantes e longevos periódicos latino-americanos de Ciências Sociais, particularmente nas áreas de Ciência Política e Sociologia.

Esse meio século foi também contemporâneo da institucionalização das Ciências Sociais no país, com a criação de inúmeras instituições de 
pesquisa, cursos de pós-graduação nos níveis de mestrado e doutorado, associações representativas das Ciências Sociais, como a Associação Nacional de Pós-Graduação e Pesquisa em Ciências Sociais (Anpocs) em 1977, a Sociedade Brasileira de Sociologia (SBS) retomada em 1987 e a Associação Brasileira de Ciência Política (ABCP) em 1996, que vieram se juntar à já existente Associação Brasileira de Antropologia (ABA), fundada em 1955. Da mesma forma, consolidou-se uma infraestrutura de instituições e de mecanismos de apoio à divulgação científica, particularmente de apoio às revistas no âmbito das principais instituições de fomento à pesquisa, como o Conselho Nacional de Desenvolvimento Científico e Tecnológico (CNPq), a CAPES, a Financiadora de Estudos e Projetos (FINEP) e a Fundação de Amparo à Pesquisa do Estado de São Paulo (FAPESP), que serviu de modelo para as demais fundações regionais de apoio, como a Fundação de Amparo à Pesquisa do Estado do Rio de Janeiro (FAPERJ). Destaca-se, finalmente, por seu papel na profissionalização das publicações técnico-científicas, na formação de editores e de pessoal especializado, e na geração de espaços de intercâmbio de ideias e de desafios comuns, a Associação Brasileira de Editores Científicos (ABEC), da qual tive a honra de ser presidente no início dos anos 1990, o único da área de humanas até o momento.

Como principal responsável pela edição de DADOS, de 1976 até recentemente (no início, como coordenador editorial; depois, como editor adjunto, coeditor, editor e, por fim, como editor emérito), pretendo, neste breve artigo-depoimento, recuperar alguns fatos ligados à edição da coleção da revista ao longo de seus 50 anos (1966-2016). Assim, para analisar as principais mudanças no processo decisório, nos projetos editoriais e na recepção da revista pelos mais importantes indexadores nacionais e estrangeiros, as diferentes fases de DADOS encontram-se divididas pelas periodicidades adotadas durante sua existência - semestral, quadrimestral e trimestral. A trajetória da revista é associada também a transformações mais amplas do contexto político, intelectual e da editoração científica.

\section{DADOS - SEMESTRAL (1966-1977)}

A criação de DADOS se deu em momento significativamente dramático para a sociedade brasileira. O país passava pelos primórdios do golpe de Estado de 1964 e, particularmente, pela ressaca do chamado Ato Institucional no 2/1965, que abriu caminho para vários outros ${ }^{3}$. Esses 
atos foram os principais instrumentos do arbítrio. Vigoraram acima das constituições e se autodeclararam irrecorríveis perante o Poder Judiciário. Enfim, viviam-se momentos de intimidação típicos dos regimes autoritários, com a universalização da suspeita e a punição por crimes pretéritos. Na esteira do arbítrio, importantes instituições de pesquisa avançada no país desapareceram. No Rio de Janeiro, o Centro Latino-Americano de Pesquisas em Ciências Sociais (CLAPCS), o Instituto Superior de Estudos Brasileiros (ISEB) e o Instituto de Ciências Sociais (ICS), da então Faculdade Nacional de Filosofia, da Universidade do Brasil, hoje Universidade Federal do Rio de Janeiro (UFRJ), são descontinuados, levando consigo importantes periódicos acadêmicos - como América Latina, do CLAPCS, e a Revista de Ciências Sociais, do ICS (Tavares de Almeida, 1987) - e estreitando o debate acadêmico.

Os responsáveis pela criação de DADOS, liderados inicialmente por Candido Mendes, tinham plena consciência das dificuldades, como bem demonstra a preocupação presente no editorial do primeiro número: "Tem-se revelado como historicamente inevitável a correlação entre o enrijecimento das estruturas de poder e a paralisia ou torpor das ciências sociais" (DADOS, no 1, 1966: 3). A criação e o fortalecimento de instituições de pesquisa no período constituíram, sem dúvida, uma ação de resistência ao regime autoritário.

Nesse contexto, DADOS é criada, em 1966, com a previsão de publicar dois números por ano, periodicidade que prevaleceu, com dificuldades, do número 1 ao 16 . O projeto gráfico foi de autoria do artista gráfico Rogério Duarte, importante ícone do movimento tropicalista ${ }^{4}$ que, seguindo o estilo clássico do journal acadêmico, reproduziu o sumário na primeira capa, a diagramação do miolo em duas colunas, a composição em linotipia e a impressão em tipografia. A diferenciação dos números era estabelecida pelas variações das cores das capas (vermelho, verde, azul e amarelo).

A maioria dos números publicados nesse período continha um tema central ${ }^{5}$, outros artigos, relatórios de pesquisa, cronologias, resenhas de livros e pequenas comunicações. Com exceção dos artigos, os outros textos não apareceram em todos os números. De acordo com nota editorial do número 7, em 1970, a partir de então o "tema principal de cada número ficará sob a responsabilidade de um editor de tema que coordenará os vários artigos em função de um marco teórico" (DADOS, no 7, 1970:3). 
Segundo fui informado mais tarde, a edição do tema era muito interessante, mas contribuía para os atrasos constantes da revista.

A periodicidade era irrealista. Dez anos depois, em 1976, quando assumi a responsabilidade de coordenador editorial sob a edição de Simon Schwartzman, a revista encontrava-se ainda no número 11 , sendo um exemplar duplo, o 2/3. Na realidade, tratava-se de um anuário, e não de um periódico. Tive a oportunidade de editar mais cinco números dentro do critério da semestralidade, sem o tema central, com dificuldades motivadas pela inexistência de um fluxo regular de artigos e pelo amadorismo do módulo editorial patrocinado pela instituição mantenedora do Instituto Universitário de Pesquisas do Rio de Janeiro (o antigo IUPERJ), vinculado ao então Conjunto Universitário Candido Mendes ${ }^{6}$.

Embora o salário para o responsável pela condução da revista fosse de um professor do staff (como era chamado o conselho diretor na época) em tempo parcial, os recursos para tradução, versão, revisão e, sobretudo, para pagamento de composição, impressão e acabamento da revista não eram automáticos. As tiragens eram exageradas (na casa de 3 mil exemplares), sob a justificativa de que uma tiragem maior diminuiria o preço unitário. O resultado foi um encalhe superlativo, que motivou a gradativa diminuição da tiragem. As vendas e as assinaturas eram administradas pela secretaria da revista. Algumas livrarias aceitavam os exemplares para venda em consignação, mas, noventa dias depois, devolviam os pacotes, na maioria das vezes, praticamente intactos. As assinaturas eram reduzidas. $O$ forte da distribuição eram as doações. Prevalecia ainda certo amadorismo em todo o processo de produção gráfica e editorial. Apesar da boa vontade da "Praça XV" na pessoa de Candido Mendes, reitor do Conjunto Universitário, a irregularidade dos recursos impedia um planejamento editorial mais eficaz. O trabalho com Simon Schwartzman, entretanto, era gratificante. Discutíamos sobre o verdadeiro sentido de um periódico acadêmico. Começamos a fazer reuniões após as edições para avaliar os erros, que eram muitos, mas também os acertos.

Por meio do contato com editores de outras áreas - sobretudo da biomédica -, demos início à adaptação de DADOS às demandas de uma revista estritamente acadêmica: criação de um conselho editorial, formado por mim e pelos pesquisadores seniores do antigo IUPERJ, quando começamos a selecionar os artigos mediante um incipiente sis- 
tema de peer review, logo aperfeiçoado para o duplo-cego, algo inusitado nos periódicos de Ciências Sociais até então; adoção do International Standard Serial Number (ISSN), registro obrigatório e condição sine qua non para a solicitação de inscrição nos indexadores; identificação da data de recebimento e de aprovação dos artigos; publicação das informações aos colaboradores, com clara definição da missão da revista, das normas para a apresentação de artigos e das regras do jogo para a tramitação dos manuscritos apresentados.

A escassez de recursos começou a mudar com a assinatura de um convênio com a Biblioteca Nacional para a publicação do Boletim Informativo e Bibliográfico de Ciências Sociais (BIB) como suplemento de DADOS. A Fundação Ford dispôs de um recurso para documentação em Ciências Sociais e credenciou a Biblioteca Nacional, então dirigida por Jannice Monte-Mór - através do Subgrupo de Documentação em Ciências Sociais, composto por Aydil Carvalho Preis (História, Universidade Federal Fluminense - UFF), Charles Pessanha (IUPERJ), Gilberto Velho (Programa de Pós-Graduação em Antropologia Social - PPGAS, Museu Nacional, UFRJ) e Lúcia Lippi Oliveira (Centro de Pesquisa e Documentação de História Contemporânea do Brasil da Fundação Getulio Vargas - CPDOC-FGV) - para elaborar a proposta de utilização de recursos. Apresentamos, Lúcia Lippi e eu, o projeto do BIB com o objetivo de estimular a organização de uma rede de intercâmbio e de cooperação institucional e científica. Aprovado e iniciado o projeto, o conteúdo de cada número era composto pelo perfil institucional das instituições brasileiras de Ciências Sociais; pesquisas em andamento e teses e dissertações defendidas nos diversos programas de pósgraduação; artigos sobre problemas do ensino e a pesquisa; e, principalmente, resenhas bibliográficas.

O convênio com a Biblioteca Nacional trouxe um aporte considerável de recursos que permitiu dar uma postura mais profissional às edições de DADOS, planejar as edições e mais tarde, como veremos, passar a publicar três números por ano, além de contratar melhores gráficas e profissionais freelancers. A edição do número 15 de DADOS já apresenta mudanças, com a utilização das capas internas: a segunda capa traz o expediente (contendo a missão da revista, o corpo editorial e informações sobre a administração da revista, anteriormente no interior da publicação); a terceira contém as informações aos colaboradores; e a quarta capa, finalmente, com informações sobre os números passados. Tratava-se, na realidade, do projeto original de Rogério Duarte, mo- 
dernizado pelo diagramador Antonio Seara. A diferença foi o tratamento gráfico mais esmerado, com composição e impressão em offset. O registro mais importante, entretanto, foi o estrito cumprimento da periodicidade anunciada.

\section{DADOS - QUADRIMESTRAL (1978-1997)}

A periodicidade quadrimestral, na realidade, contempla vários períodos. O primeiro, que dura entre 1978 e 1980, mantinha, como vimos, o projeto gráfico original. Mesmo com a publicação ocorrendo três vezes por ano, os exemplares de DADOS continuavam sendo numerados isoladamente, em desacordo com a norma internacional, que previa a reunião dos exemplares em volumes anuais, com numeração de páginas de um a infinito. Além disso, a publicação do $B I B$, dado o interesse de seu conteúdo, ajudou na divulgação de DADOS. Em tempos de institucionalização das Ciências Sociais, o BIB teve papel importante para gerar convergência e visibilidade dos debates e das iniciativas existentes.

Tanto o projeto original quanto a publicação do $B I B$ como suplemento terminam no número $22^{7}$; da mesma forma, a numeração em números isolados. Arbitramos o próximo número como volume 23, composto de três fascículos numerados consecutivamente. A segunda fase da periodicidade quadrimestral é iniciada em 1980, com o volume 23.

Nessa segunda fase, um novo projeto editorial é inaugurado. A primeira novidade foi a mudança do nome da revista. A marca DADOS havia sido registrada pela Editora Três no Instituto Nacional da Propriedade Industrial (INPI), que considerava ilegal sua utilização. Com o auxílio de advogados, registramos a marca DADOS - Revista de Ciências Sociais. O volume 23/1, de 1980, é um número que, como o primeiro, pode ser considerado histórico. Inaugura o convênio com a Editora Campus, subsidiária da Elsevier Science Publishers, uma das maiores editoras de journals do mundo. Um novo projeto gráfico, concebido pelo departamento de criação da Campus, substitui o original, com espaço suficiente para a chamada dos temas e/ou artigos mais importantes do conteúdo de cada número e mantendo as cores básicas. O processo decisório também é modificado. Um novo conselho científico foi composto, formado pelos editores, por editores associados, por um conselho editorial (formado pelos professores pesquisadores do antigo IUPERJ) e um conselho consultivo (formado por professores pes- 
quisadores seniores das melhores instituições de pesquisa em Ciências Sociais no país), vencendo resistências internas.

Além disso, a oferta de artigos obrigou a utilização dos avaliadores ad hoc, também recrutados entre os profissionais atuantes nas instituições importantes do país e, mais tarde, do exterior, cujas participações seriam registradas nos últimos números de cada volume, em uma tentativa de manter o anonimato da arbitragem. Com o tempo, a participação desses avaliadores, como veremos mais adiante, vai se tornar majoritária. Outra novidade do convênio foi o abandono da preocupação com a venda de assinaturas nacionais e estrangeiras, e de números avulsos, cuja responsabilidade passou a ser da editora. Outro dado importante foi a inclusão da revista no Catálogo de Journals da Elsevier ${ }^{8}$, distribuído anualmente na Feira do Livro de Frankfurt.

Embora não seja objetivo deste texto falar do conteúdo da coleção, pois outros artigos deste número cuidam disso, abro exceção para ressaltar, também no campo substantivo, a relevância do volume 23/1. Essa edição coincidiu com o lançamento dos cursos de doutorado em Ciência Política e em Sociologia do antigo IUPERJ, cujo paraninfo foi o ministro Victor Nunes Leal. Sua trajetória foi devidamente registrada em artigo de abertura de José Murilo de Carvalho, intitulado “Em Louvor de Victor Nunes Leal", seguido de um texto do próprio Victor Nunes Leal, "O Coronelismo e o Coronelismo de Cada Um", apresentado originalmente em março de 1980, na abertura do doutorado do instituto. Os demais artigos, por sua vez, traçam uma discussão crítica sobre o significado de fazer Ciências Sociais no Brasil, com balanços e interpretações sobre a Ciência Política, a Sociologia e a Antropologia, assinados por Wanderley Guilherme dos Santos, "A Ciência Política na América Latina: Nota Preliminar de Autocrítica"; Bolívar Lamounier, "Pensamento Político, Institucionalização Acadêmica e Relações de Dependência no Brasil"; Fabio Wanderley Reis, "O Grifo é Nosso! Academia, Democracia e Dependência"; Otávio Guilherme Velho, "Antropologia para Sueco Ver"; e Maria Valéria Junho Pena, “Uma Nova Sociologia?".

O novo projeto contemplava ainda a publicação de um ensaio bibliográfico, que não esteve presente em todos os números subsequentes. Ademais, o número seguinte começou a enumerar os indexadores de DADOS, com destaque para o então Current Contents, hoje Thomson Reuters, do Institute for Scientific Information (ISI), o mais importante deles, como veremos mais adiante. 
Na ocasião, DADOS passa a integrar, em sua fundação, o Programa de Apoio às Publicações de Revistas CNPq-FINEP, posteriormente

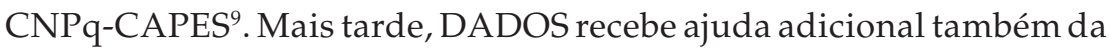
FAPERJ. Esses recursos eram destinados basicamente às fases de impressão e acabamento da revista. Coube ao antigo IUPERJ (e cabe até hoje ao atual IESP-UERJ) - por meio da direção executiva e da direção de publicações do instituto, com o apoio e o empenho do editor - a contrapartida para o pagamento de pessoal e, eventualmente, para o empréstimo de recursos correspondentes do programa, cujas verbas eram liberadas, geralmente, no final do ano, em clara contradição com os requisitos de financiamento, que consideravam a periodicidade uma regra de ouro para a continuidade do recebimento dos recursos.

Encerrado o convênio com a Campus, a DADOS - Revista de Ciências Sociais passa a ser editada sucessivamente pelas editoras Taurus, Espaço e Tempo, Vértice e Rio Fundo até 1993, sem a visibilidade alcançada pelo convênio com a Campus e com o retorno da produção gráfica e do fantasma de venda em livrarias e assinaturas, administrada pelo Setor de Publicações do IUPERJ.

Ainda com a periodicidade quadrimestral, a DADOS inaugura, no início da década de 1990, um novo projeto gráfico, de autoria de Antoninho de Paula, então diagramador do Jornal do Brasil. Qualquer modificação na revista contava com a resistência de alguns fundadores. Abandonar as quatro cores-base (vermelho, verde, azul e amarelo) e adotar uma capa branca, com pequenos fios que lembravam as quatro cores anteriores, como na mudança precedente, não foi uma tarefa das mais fáceis (vol. 33, 1990). Outras modificações ocorreriam. O volume 35/3, de 1992, finalmente acabou com a dualidade de conselhos e criou um único conselho editorial, formado por profissionais de fora do antigo IUPERJ representando diferentes instituições de pesquisa e de pós-graduação do país. Essa mudança, há muito desejada, era o reconhecimento de uma realidade que se impôs ao longo dos anos: a DADOS como revista da comunidade de Ciências Sociais do Brasil, com o uso sistemático do sistema de avaliação por pares duplos-cegos para a seleção dos artigos. Da mesma forma, foram extintos os editores associados e criado um conselho de redação, formado por pesquisadores do instituto, de áreas distintas, com mandato de dois anos, e do editor para colaborar sobretudo com o recebimento e a tramitação dos artigos no processo de peer review. 
O volume 39/3, de 1996, inaugura, por sua vez, a publicação eletrônica. DADOS fez parte dos 11 títulos iniciais da hemeroteca SciELO, sendo o único periódico da área de Ciências Sociais. O SciELO começa a resolver o maior problema do livro brasileiro, amplificado nas revistas acadêmicas: a distribuição. Além disso, a questão das vendas passa para segundo plano, pois uma das condições para a participação no SciELO é o acesso livre (open access). Pouco mais tarde, finalmente a revista encerra a publicação quadrimestral.

\section{DADOS - TRIMESTRAL (1998-...)}

No volume 41/1, de 1998, DADOS adota, por fim, a periodicidade trimestral, sem dúvida a frequência mínima ideal para os periódicos acadêmicos. Muitas revistas internacionais de tradição utilizam as estações do ano para a identificação dos fascículos constantes do volume. O importante da fase que se inicia, contudo, é a consolidação da publicação eletrônica. Ainda nesse período, teve início a publicação de artigos em inglês. DADOS é convidada a fazer parte do SciELO Social Sciences - English Edition (SSS) ${ }^{9}$, produto do esforço conjunto entre o SciELO e o Centro Edelstein de Pesquisas Sociais, aqui representado pelo professor Bernardo Sorj, com o apoio da Open Society. O objetivo explícito do SSS foi "promover o acesso internacional às revistas científicas de Ciências Sociais na América Latina" mediante a "disponibilização dos textos em inglês, gratuitamente, com vistas a aumentar a visibilidade e a acessibilidade ${ }^{\prime 10}$. Foram publicados cinco volumes anuais, entre 2005 e 2010, contendo artigos lançados no ano anterior a cada volume. O projeto, porém, foi encerrado com o término do recurso inicial e o desinteresse de outra instituição para financiar sua continuidade. Entretanto, a questão da publicação em inglês foi reaberta mais recentemente, como veremos, com um novo projeto editorial de internacionalização da revista.

Os anos seguintes foram de consolidação e de aprimoramento da revista DADOS. O processo de avaliação passou majoritariamente para os consultores ad hoc, complementando o conselho editorial e acompanhando o crescimento da comunidade acadêmica e o aumento da submissão de artigos. Essa evolução pode ser constatada nas notas editoriais, ao final de cada volume, que registram o agradecimento à colaboração desses avaliadores no controle de qualidade acadêmica de DADOS. Outra área de permanente aprimoramento foi o cuidado com a editoração dos textos publicados, isto é, um rígido respeito às 
normas que regem o texto acadêmico, incluindo títulos, resumos, notas, gráficos, tabelas, ilustrações, citações e referências bibliográficas, em concordância com os mais conceituados manuais de estilo. Ao longo dos anos, a redação de DADOS contou com a colaboração de excelentes profissionais de edição de textos acadêmicos, consolidados na secretaria de redação da revista. Esses profissionais, alguns treinados diretamente na $\mathrm{ABEC}$ ou indiretamente, por meio de seus textos, contribuíram efetiva e imensamente para o texto de DADOS e merecem destaque especial. São eles: Beth Cobra, Claudia Boccia, Elisabeth Lissovsky, Maria Alice Silva Ramos, Patrícia Campos de Souza, Márcia Rinaldi de Mattos, Mônica Farias, Sabrina Primo e Tema Pechman.

A década de 2010, contudo, teve início com o agravamento da crise do antigo IUPERJ. Uma diminuição de recursos, que afetou o cumprimento de toda a folha de pagamento, teve como consequência salários atrasados e demissão de pessoal administrativo. A DADOS não ficou imune à crise. O Setor de Publicações do instituto perdeu seus dois funcionários que atuavam também como secretários de redação. A parte administrativa ficou limitada à secretária, também sem receber remuneração de forma regular. Falava-se abertamente sobre a descontinuidade da revista, o que gerou a diminuição da apresentação de artigos e, por consequência, dificuldades para fechar os quatro números anuais. Ademais, a perda do e-mail iuperj.br e as dificuldades administrativas trouxeram um princípio de caos à tramitação dos artigos, com prejuízos consideráveis. Mesmo com todas essas dificuldades, o importante é que a DADOS, com o apoio decisivo da comunidade acadêmica e o empenho da diretoria e dos docentes do instituto, cumpriu todos os compromissos com a periodicidade, editando todos os números previstos no delicado momento de transição institucional dos discentes e de grande parte dos docentes do antigo IUPERJ para a UERJ, com a criação, em junho de 2010, do IESP. Após a fundação do IESP-UERJ, me desliguei da editoria da revista dois anos depois, em 2012, colaborando com a transição como coeditor e, até hoje, como membro do conselho de redação a partir de minha nomeação como editor emérito.

Começa, assim, em 2013, com o competente Breno Bringel, a nova fase de DADOS. O fluxo da revista é progressivamente reorganizado, e a demanda de artigos recebidos cresce de forma vertiginosa, conforme apontado em nota editorial no volume 59, no 2, de 2016 ${ }^{11}: 170$ artigos em 2012; 372 em 2013; 495 em 2014; e 393 em 2015. Um alívio. A revista es- 
tava salva. Diante desse novo cenário, algumas medidas importantes foram tomadas para ajudar a política editorial e os procedimentos de avaliação e de gestão de artigos, a saber: reformulação do escopo e da política editorial, que se torna mais estrita; redefinição do fluxo editorial, que torna os filtros iniciais de avaliação mais rigorosos; e adoção de um novo sistema de gestão online de manuscritos, na plataforma ScholarOne Manuscripts, com o objetivo de maximizar a eficiência do processo de avaliação. Embora a taxa de rejeição aumente, o número de artigos publicados também cresce.

Um dos traços importantes dessa nova fase é a abertura da revista à publicação de textos em espanhol, bem como de artigos em inglês, que se inicia neste número, dependendo do teor do artigo e da decisão final do conselho de redação, que poderá sugerir a publicação simultânea em português/espanhol e em inglês. Sumários e resumos em espanhol foram acrescentados aos de português, inglês e francês. Com isso, a demanda e a presença de pesquisadores estrangeiros aumentaram, especialmente do espaço ibero-americano, como autores e como proponentes de artigos ( $47 \%$ dos artigos submetidos à revista no último ano procederam do exterior, sendo a maioria esmagadora da Espanha, de Portugal e de diversos países da América Latina), e também como avaliadores (hoje aproximadamente $20 \%$ ), reforçando uma vocação presente desde o início da revista DADOS.

Embora os recursos disponíveis não permitam a recomposição do antigo corpo administrativo - uma secretária e duas secretárias de redação, em tempo integral -, o que leva a edição dos textos a ser realizada por profissionais freelancers, a revista tem mantido o cumprimento das edições e buscado, ao mesmo tempo, se adaptar aos novos tempos, por exemplo, com a presença nas redes sociais, por meio de contas ativas no Facebook e no Twitter, além de outra, recém-criada, no Academia.edu. Novidades na divulgação também estão sendo estudadas, bem como algumas inovações no terreno da ética na pesquisa, que devem aparecer ainda em 2017, junto com um novo site próprio da revista. Para isso, o trabalho das atuais colaboradoras de DADOS é essencial: nos últimos anos, uniram-se a Claudia Boccia, no dia a dia da revista, em tempo parcial, Marcelle Maldonado, Marina Bezerra, Marcia Rangel Candido e, mais recentemente, Ana Carolina Santos do Nascimento.

Por fim, a receptividade de DADOS, nos últimos anos, pode ser medida ainda por sua participação nos índices de referência. De acordo com 
Packer (2014: 305), "a indexação em si é um atributo para a qualificação dos periódicos e que, quanto melhor a posição que detém nos rankings dos índices, maior é o prestígio que adquirem na comunidade acadêmica e nos sistemas de avaliação". Nesse sentido, DADOS não somente participa dos mais importantes - merecendo destaque sua inclusão no Current Contents, do ISI, hoje Thomson Reuters, e no Scientific Journal Rankings (SJR), e consequentemente nas bases WoS, Scopus, Scimago Journal \& Country Ranks ${ }^{12}$ - como tem melhorado de forma significativa seu desempenho nesses índices. No último SJR, o fator de impacto de DADOS cresceu de modo significativo, sendo superior ao de importantes revistas brasileiras e latino-americanas, como a Revista de Ciencia Política (RCP) do Chile, Política y Gobierno, do México, e latino-americanistas, como a Latin American Research Review (LARR), da Latin American Studies Association (LASA).

Ainda no Brasil, merece menção a presença destacada no Qualis Periódicos, da CAPES, sistema usado para classificar a produção científica dos programas de pós-graduação considerando os artigos publicados em periódicos científicos. Como é sabido, tem influência direta na produção do pesquisador individual, bem como nas instituições de pesquisa. Desde o início de sua criação, DADOS vem sendo classificada no topo mais alto das notas atribuídas (hoje A1) em suas principais áreasalvo (Ciência Política e Sociologia), além de outras áreas conexas.

\section{CONSIDERAÇÕES FINAIS}

As revistas científicas, costuma-se dizer, têm alta taxa de natalidade acompanhada de alta taxa de mortalidade. A decisão dos fundadores e dos pesquisadores do antigo IUPERJ (e do atual IESP-UERJ) de criar uma revista, mantê-la na estrutura da casa e fornecer permanente contrapartida aos recursos públicos criados, posteriormente, pelas agências de fomento é, sem dúvida, fator-chave para explicar a longevidade de DADOS. Acrescenta-se a isso o fato de a revista contar com um crescente processo de profissionalização. Sobreviver, entretanto, não é o mais importante para uma revista científica. Servir como referência nas áreas em que atua é o grande desafio do periódico científico e pré-requisito indispensável para atrair bons autores e avaliadores. A melhor forma de obter o respeito da comunidade de referência, no Brasil e no exterior, é incorporá-la ao processo de seleção de artigos mediante um processo de arbitragem sistemático, impessoal, em que todos os artigos são submetidos, sem exceção, ao crivo dos avaliadores. 
A revista DADOS não se contentou com a periodicidade semestral do início. Com o objetivo de aumentar a frequência de sua circulação, passou para a fase quadrimestral e, por fim, para a trimestral. Desenvolvidos os requisitos mínimos de um periódico científico, DADOS participou dos melhores programas de apoio à publicação de revistas acadêmicas no Brasil. Sua presença em importantes indexadores, como WoS, Scopus e sobretudo SciELO, aumentou sua visibilidade. Apesar da existência de um razoável sistema de apoio às revistas estabelecido pelo CNPq, pela CAPES e pela FAPERJ, o fluxo de recursos para a produção das revistas permanece incerto.

DADOS representa um belo exemplo de projeto coletivo desenvolvido por uma comunidade acadêmica específica. Nucleada no antigo IUPERJ e hoje no IESP, contou com a colaboração de profissionais prestigiados das Ciências Sociais no país e no exterior. Esse conjunto de autores e/ ou avaliadores constitui o que costumo chamar de "comunidade DADOS". Seu papel é fundamental na continuidade do projeto. Felizmente a comunidade acadêmica brasileira não aceitou o "possível enrijecimento das Ciências Sociais" aludido no editorial do primeiro número de DADOS. Ao contrário.

De minha parte, renovo a satisfação de ter participado do projetoDADOS e de ter contribuído para a criação das principais instituições de divulgação científica nas últimas décadas, sobretudo da ABEC e do SciELO.

(Recebido para publicação 14 de setembro de 2016) (Aprovado 2 de dezembro de 2016) 


\section{NOTAS}

1. Disponível em https://royalsociety.org/journals/publishing-activities/publishing350. Acesso em setembro de 2016.

2. É interessante notar que, embora as Ciências Humanas e Sociais marquem presença diminuta no WoS (6\%) e no Scopus (14\%), no SciELO alcançam 23\% do número de artigos indexados por área temática (Parker, 2014: 306).

3. Entre outras medidas, o AI-2 promoveu um aprofundamento do arbítrio: cancelou as eleições presidenciais; extinguiu os partidos políticos; subverteu o calendário eleitoral; aumentou o número de ministros do Supremo Tribunal Federal (STF) de 11 para 16; renovou a suspensão das garantias constitucionais; reabriu as cassações e as perdas dos direitos políticos.

4. Rogério Duarte, recentemente falecido (1939-2016), foi um versátil artista, intelectual e poeta. Na década de 1960, foi diretor de arte da Editora Vozes e da União Nacional dos Estudantes (UNE). Considerado o criador da estética virtual da Tropicália, foi responsável por capas de disco de alguns dos principais músicos brasileiros. Ver biografia de Duarte no Dicionário Cravo Albin da Música Popular Brasileira, disponível em http://dicionariompb.com.br/rogerio-duarte/biografia. Acesso em novembro de 2016.

5. Ver, neste dossiê especial, o já citado artigo de Christian Edward Cyril Lynch.

6. O nome oficial da instituição mantenedora era Sociedade Brasileira de Instrução (SBI).

7. A partir de então, o BIB passa a ser editado pela Anpocs, até o presente. Fui seu editor entre 1981 e 2002.

8. Ver, por exemplo, o Elsevier Science Publishers Journals, 1983, p. 392.

9. A publicação do artigo "Lost Science in the Third World"(Gibbs, 1995) gerou um grande debate sobre a acessibilidade das pesquisas produzidas na América Latina. Um dos temas discutidos foi a pouca publicação em inglês dos periódicos, daí a importância do programa.

10. Disponível em socialsciences.scielo.org. Acesso em setembro de 2016.

11. Essa nota editorial (DADOS, vol. 59, no 2) apresenta dados e informações relevantes sobre o fluxo e o perfil dos artigos recebidos durante o último ano (número de artigos submetidos; distribuição da autoria por titulação acadêmica, gênero e lugar de origem), apontando também para algumas das características e desafios da atual fase da revista.

12. DADOS foi admitida no ISI - Thomson Reuters em 1991 e, por muito tempo, foi não apenas o único periódico de Ciências Sociais do Brasil a fazer parte desse indexador, mas também o único em língua portuguesa. A revista entrou no WoS em 1998, e os primeiros indicadores no Journal of Citation Reports (JCR) apareceram em 2001. 


\section{REFERÊNCIAS BIBLIOGRÁFICAS}

AMORIM NETO, Octavio. (2010), “A Política Comparada no Brasil: A Política dos Outros", in R. Lessa (org.), Horizontes das Ciências Sociais no Brasil: Ciência Política. São Paulo, Anpocs, pp. 321-340.

GIBBS, Wayt W. (1995), "Lost Science in the Third World". Scientific American, vol. 273, no 2, pp. 92-99.

LEITE, Fernando. (2015), O Campo de Produção da Ciência Política Brasileira Contemporânea: Uma Análise Histórico-Estrutural de seus Princípios de Divisão a partir de Periódicos, Áreas e Abordagens. Tese (Doutorado em Sociologia), Setor de Humanas, Letras e Artes, Universidade Federal do Paraná, Curitiba.

. (2016), "The Stratification of Diversity: Measuring the Hierarchy of Brazilian Political Science". Brazilian Political Science Review, vol. 10, no 1, pp. 1-29.

;CODATO, Adriano. (2013), "Autonomização e Institucionalização da Ciência Política Brasileira: O Papel do Sistema Qualis-Capes”. Agenda Política, vol. 1, no 1, pp. $1-21$.

MARENCO, André. (2016), “Cinco Décadas de Ciência Política no Brasil: Institucionalização e Pluralismo", in L. Avritzer; C. Milani; M. S. Braga (orgs.), A Ciência Política no Brasil: 1960-2015. Rio de Janeiro, Editora FGV, pp. 141-162.

MARQUES, Danusa. (2007), Democracia e Ciências Sociais no Brasil (1985-2005). Dissertação (Mestrado em Ciência Política), Instituto de Ciência Política, UnB, Brasília.

NICOLAU, Jairo; OLIVEIRA, Lilian. (2013), "A Produção de Ciência Política Brasileira: Uma Análise da Produção de Artigos Acadêmicos". Anais do 37o Encontro Anual da Anpocs, Águas de Lindoia, São Paulo.

OLIVEIRA, Lilian P. da Costa. (2016), A Trajetória da Ciência Política Brasileira: Uma Análise da Produção e da Formação Acadêmica (1966-2014). Tese (Doutorado em Ciência Política), Departamento de Ciência Política, Instituto de Estudos Sociais e Políticos, UERJ, Rio de Janeiro.

PACKER, Abel. (2014), "A Eclosão dos Periódicos do Brasil e Cenários para o seu Porvir". Educação e Pesquisa, vol. 40, no 2, pp. 301-323.

TAVARES DE ALMEIDA, Maria Hermínia. (1987), “Castelos na Areia: Dilemas da Institucionalização das Ciências Sociais no Rio de Janeiro (1930-1964)". Boletim Informativo e Bibliográfico de Ciências Sociais - BIB, no 24, pp. 41-60. 


\section{RESUMO}

50 Anos de DADOS - Revista de Ciências Sociais: Uma Introdução à Coleção

Neste artigo-depoimento o autor, responsável pela edição de DADOS - Revista de Ciências Sociais por mais de três décadas, realiza uma introdução ao acervo construído ao longo dos 50 anos de publicação da revista (1966-2016). As diferentes fases da revista são divididas pelas periodicidades adotadas ao longo destas cinco décadas (semestral, quadrimestral e trimestral) para analisar as principais mudanças no processo decisório, nos projetos editoriais e na recepção da revista pelos mais importantes indexadores nacionais e estrangeiros. A trajetória da revista é associada também a transformações mais amplas do contexto político, intelectual e da editoração científica.

Palavras-chave: DADOS - Revista de Ciências Sociais; coleção de DADOS; indexadores; editoria científica

\section{ABSTRACT \\ 50 Years of DADOS - Revista de Ciencias Sociais: An Introduction to the Collection}

Written by the editor of DADOS - Revista de Ciências Sociais for over three decades, the following article-report provides an introduction to the archive formed over the 50 years since the journal's first publication (1966-2016). The various phases of the journal are divided into the periods adopted over the five decades (biannual, four-monthly and quarterly) in order to analyze the main shifts in the decision-making process, editorial projects and in the receiving of the journal by the main national and international indices. The path taken by the journal over the years is also linked to wider transformations to the political and intellectual context, as well as that of scientific publishing.

Keywords: DADOS - Revista de Ciências Sociais; DADOS collection; indices; scientific publishing 


\section{RÉSUMÉ}

50 Ans de DADOS - Revista de Ciências Sociais: Panorama de la Collection

Dans cet article-témoignage, l'auteur, responsable de la rédaction de DADOS Revista de Ciências Sociais pendant plus de trente ans, propose un panorama de la collection constituée au long des 50 ans de publication de la revue (1966-2016). Les différentes phases de la revue sont divisées en fonction de sa périodicité (semestrielle, quadrimestrielle et trimestrielle) dans le but d'analyser les principaux changements intervenus dans les processus décisionnels, dans les projets éditoriaux et dans la réception de la revue par les systèmes d'indexation nationaux et étrangers les plus importants. Nous verrons que la trajectoire de la revue est également associée à des transformations plus amples du contexte politique, intellectuel et de l'édition scientifique

Mots-clés: DADOS - Revista de Ciências Sociais; collection DADOS; indexation; édition scientifique

\section{RESUMEN}

50 Años de DADOS - Revista de Ciências Sociais: Una Introducción a la Colección

En este artículo-testimonio el autor, responsable de la edición de DADOS Revista de Ciências Sociais por más de tres décadas, hace una introducción al acervo construido a lo largo de los 50 años de publicación de la revista (1966-2016). Las diferentes etapas de la revista se dividen por las periodicidades adoptadas a lo largo de estas cinco décadas (semestral, cuatrimestral y trimestral) para analizar los principales cambios en el proceso de decisión, en los proyectos editoriales y en la recepción de la revista por los más importantes indexadores nacionales y extranjeros. La trayectoria de la revista se asocia también a transformaciones más amplias en el contexto político, intelectual y de la edición científica.

Palabras clave: DADOS - Revista de Ciências Sociais; colección de DADOS; indexadores; editora científica 